\title{
An Empirical Study on the Attrition Sequence of English Interrogative Structures in Chinese Context*
}

\author{
Yan Liu \\ Zhongbei College, Nanjing Normal University, Nanjing, China \\ Email: anyingzhai@163.com
}

Received 5 September 2014; revised 20 October 2014; accepted 4 November 2014

Copyright (C) 2014 by author and Scientific Research Publishing Inc.

This work is licensed under the Creative Commons Attribution International License (CC BY).

http://creativecommons.org/licenses/by/4.0/

(c) (i) Open Access

\section{Abstract}

In view of the important role that language attrition plays in language learning and teaching, this study is designed to probe into Chinese adult EFL learners' attrition sequence of English interrogations. The participants investigated in this study are 243 Chinese EFL graduates who had graduated for at least two years. The main measurement employed is a questionnaire, with 40 items of English interrogative sentences included. It is detected that the attrition sequence roughly reflects the inversed pattern of acquisition sequence of English interrogations in Chinese context, which echoes with the assumption of Jakobson's Regression Hypothesis. The findings also shed light on English teaching and learning in China. As Regression Hypothesis suggests that language components might be lost in the reverse order in which they are acquired, learners are expected to timely review acquired language skills prone to attrition. In addition, it is hoped that understanding some of the dynamic processes of language retention and attrition will increase teachers' and learners' awareness and ability to make their own personal observations and to help keep EFL learners' language abilities.

\section{Keywords}

Language Attrition, English Interrogation, Attrition Sequence, Regression Hypothesis

\section{Introduction}

At present, a considerable body of research has been carried out in the field of language acquisition. An intri-

*This paper is a partial fulfillment of the Program for the Philosophy and Social Sciences Research of Higher Learning Institutions of Jiangsu Province (Number: 2014SJD127). 
guing question which has attracted hardly any attention is: how much of these (often laboriously) acquired skills are retained over longer periods of time when they are not being used? Only up to 1980, however, did the issue start to attract some scholarly attention and did language attrition become a formal discipline in the filed of language research.

As the inverse process of language acquisition, language attrition, sometimes called language loss (Pauwels, 1986) or language death (Schmidt, 1985), refers to the loss of any language or any portion of a language by an individual or a speech community. It's the phenomenon that learners' ability of using an acquired language regresses with time due to cease or reduction of use (Ni, 2006).

The recent three decades have witnessed a rapid development of language attrition research, both theoretically and empirically (Ecke, 2004, 2013). At the same time, many theories and hypotheses were then put forward to describe and explain language attrition, including Regression Hypothesis (Jakobson, 1941; de Bot \& Weltens, 1991), Activation Threshold Hypothesis (Paradis, 1993), Inverse Hypothesis (Vechter, Lapkin, \& Argue, 1990), Critical Threshold Theory (Jimenez, 2003: p. 40), and Linguistic Feature Hypothesis (de Bot \& Weltens, 1991) etc.

Among them, the Regression Hypothesis is a significant one, describing attrition sequence, i.e. the order in which a linguistic feature is attrited. It advocates that language components might be lost in the reverse order in which they are acquired, i.e. the attrition sequence is "a recapitulation in reverse of the acquisition sequence" (Hansen, 1980: p. 169). Some of the attempts at confirming the Regression Hypothesis have been successful for certain specific syntactic structures and in limited language contexts (such as the attrition sequence of English negative structures in Japanese context, the attrition sequence of Japanese negative structures in English context etc.). In this sense, it is meaningful to conduct a study to demonstrate the explanatory power of this hypothesis in explaining the attrition of interrogative structures in Chinese context.

\section{Literature Review}

\subsection{Acquisition Sequence of English Interrogations for EFL Learners}

Language attrition has been regarded to be the reverse process of language acquisition. It is thus necessary to explore the acquisition sequence when conducting the research into an attrition sequence.

Acquisition sequence refers to the stages that learners go through in acquiring a target language feature. It mainly deals with such questions as “How do learners gradually acquire a particular TL linguistic feature?” (Ellis, 1994: p. 73)

The first attempt on investigating EFL's English interrogation acquisition sequences was conducted by Ravem. He found that at the first stage, children seemed to be forming questions using mostly a declarative sentence word order with a rising intonation, or a question mark was added. At the second stage, inversion occurred in some yes-no questions, but not in wh-questions. At the same time, auxiliary "do" was inverted in some yes-no questions. At the last stage, negative questions appeared while some of them were formed without inversion (Ravem, 1968, 1974).

Researchers in the famous Harvard Project (Cazden, 1975) studied six Spanish speakers and found at stage l, questions were formed by marking statements with rising intonation. Wh-questions appeared at stage 2, but without subject-verb inversion, indeed often without any auxiliary verb at all. When inversion did enter the system at stage 3, over inversion also happened. Finally, at stage 4, the learners acquired the full target system, differentiating between simple and embedded questions ${ }^{1}$, inverting in the former only.

Adams (1978) analyzed the spontaneous speech of ten native-Spanish-speaking children and spotted the development of yes-no question was divided into three main stages. At the first one, declarative sentence word order was used and rising intonation was the only signal for the question. At the second stage, rising intonation was still the most common way to form yes-no questions and none of the optional auxiliary elements were present and, "do" and "be" appeared only in a few routine expressions. By the third stage be-inversion stabilized for all interrogations. At the same moment, more modals began to appear inverted in order to form the questions.

Ellis (1999: pp. 60-61) summarized L2 learners' interrogation acquisition sequences into four stages as follows. The first productive questions were intonation questions, i.e. utterances with declarative order but spoken with a rising intonation. The next development saw the appearance of productive wh-questions although there was no subject-verb inversion and the auxiliary verb was often omitted. Then, inversion occurred at this stage while subject-verb inversion didn't happen in negative interrogations. At the last stage, embedded questions

\footnotetext{
${ }^{1}$ An embedded question refers to a question or a statement in which another interrogation is embedded, such as Can you tell me who the man
} is? 
appeared with a subject-verb inversion. It was a kind of overgeneralization of inversion.

In terms of the findings above, it is explored that both L1 and L2 learners pass through the following four stages when they acquire interrogative structures.

Stage $1>$ Stage $2>$ Stage $3>$ Stage 4 (">” means "precede to acquire") $)^{2}$

Stage 1: It is a "non-communicative" stage during which learners can only produce "intonation questions", i.e. utterances with declarative word order but spoken with a rising intonation. Moreover, there are also some wh-questions at this stage, but these appear to have been learnt as ready-made chunks. For example, I am coloring?

Stage 2: Productive wh-questions appear at this stage, while there is no subject-verb inversion and the auxiliary verb is often omitted. For example, Where you work?

Stage 3: Inversion occurs at this stage and inversion with " $b e$ " tends to occur before inversion with "do". For example, Are you Shelley? She did know the thing well? However, subject-verb inversion doesn't happen in negative interrogations. For example, Why we can't go to London now?

Stage 4: Embedded questions, such as Who knows what time it is? are the last to develop. When they first appear, they have a subject-verb inversion. It is a kind of overgeneralization of inversion. In addition, there is another interrogative structure which is acquired at this stage, that is, the interrogation in which "wh-" phrase acts as the subject of the sentence. When these sentences appear, they are also inserted with an auxiliary, as in ordinary wh-question. For example, Can you tell me who are you?

\subsection{Attrition Sequence of English Interrogations for EFL Learners}

With the prevalence of Regression Hypothesis, investigations into attrition sequence become a central focus of a few studies (Olshtain 1989; Hedgcock 1991; Hayashi 1999), among which, the negative structures are the very elements studied most frequently.

One of the prominent studies was undertaken by Hansen (1999: pp. 142-153). She examined the loss of Japanese negation in 30 middle-aged Americans who learnt Japanese while working as missionaries in Japan in their early twenties. In Japanese the negators used for propositional negation are bound morphemes suffixed to the element being negated. This negated predicate can be a verb (V-Neg), noun (N-Neg), nominal adjective (NA-Neg) or adjective (A-Neg), which make up the Japanese negation structures. The cross-sectional data from over 200 missionaries learning Japanese in Japan, representatives of the same population sampled in the attrition research, yielded the following acquisition order of the Japanese negation structures: V-Neg $>\mathrm{N}-\mathrm{Neg}>$ NA-Neg > A-Neg (">” means "precede to acquire"). Learners acquired V-Neg first, followed by N-Neg, NA-Neg and A-Neg. In Hansen's attrition research, she identified the participants' attrition sequence of Japanese negative structures as follows: A-Neg > NA-Neg > N-Neg > V-Neg (">” means "precede to be attrited"). That is, A-Neg structure was attrited first, followed by NA-Neg and N-Neg, and V-Neg retained longest. Hansen explained the result by referring to the frequency of forms in the target language input and finally made a conclusion in support of the Regression Hypothesis (Li, 2008).

Hayashi (1999) documented the remains of L2 Japanese in elderly Micronesians who learned Japanese as school children during the Japanese occupation of their islands. With the analytical focus again on negation, the interview and elicitation data that were reported suggested Japanese negative structures were lost in the reverse order in which they were acquired, which also echoed with Regression Hypothesis.

\subsection{Research Questions}

Based on the EFL's acquisition sequence of English interrogations drawn from the past studies, and Regression Hypothesis, which has testified the attrition sequences of some structures, the research questions of the present study are proposed. What is the attrition sequence of English interrogations for Chinese EFL adult learners? Can Regression Hypothesis really testify this sequence?

\section{Research Method}

\subsection{Questionnaire}

One of the objectives of the present research is to testify whether the Regression Hypothesis is really applicable

${ }^{2}$ Here, a "stage" consists of a period during which learners use a particular form or structure in a systematic manner, although not necessarily to the exclusion of other forms and structures (Ellis, 1994: p. 111). 
in the interrogation attrition for Chinese EFL adult learners. Thus, we adopted the sequence of interrogation acquisition as the baseline and devised the questionnaire accordingly. And a cross-sectional paradigm and the technique-accuracy order were involved.

In the questionnaire, a grammaticality judgment task was involved. The task involved 40 sentences altogether, grammatically correct or incorrect. In every stage, there were 10 sentences. Among them, 21 sentences (with *) came from the previous studies of interrogation acquisition sequences, and the other 19 interrogative sentences were devised based on the identified four acquisition stages (see 2.1) and Chinese National English Teaching Syllabus in 1982, 1986 and 1999 (see Table 1).

In order to minimize the interference and maximize the reliability of the research, these 40 items were randomly arranged in the final questionnaire. Besides, a five-scale Likert assessing system was adopted so that the participants' attrition can be examined more precisely (see Appendix).

\subsection{Participants}

The target participants of this study were those who had graduated from non-English majors of a college or a university and have worked at least for more than 2 years. They hardly used English in their work and never received any English training or master program study after graduations. What's more, we consulted Chinese National English Teaching Syllabus and found that the target participants had been taught all the interrogative structures involved in the questionnaire even in their junior middle schools. In other words, it is likely that students have acquired the investigated structures. However, since there is no guarantee for students' acquisition of these structures, a pilot study was conducted to learn more about the population's level of acquisition. The participants in the pilot study are representatives of the same population sampled in the survey.

\subsection{Pilot Study}

In the field of language attrition research, there is a big problem. That is, it is hard to say the participants' failure in tests is a result of attrition, but not imperfect learning. The problem is easy to be solved in a longitudinal study where the participants' PLPAs (proficiency level prior to attrition) can be measured and specified, while in a cross-sectional paradigm, a common remediation is a pilot study, through which, researchers can roughly presuppose the participants' PLPAs by means of consulting those of the equivalent participants in the pilot study. This kind of method is widely used in previous attrition studies such as the one conducted by Hansen (1999). The present study is also such an attempt on this model.

In the pilot study, the questionnaires were distributed to 31 sophomore college students majoring in laws in Jiangsu Police College. The main outputs were listed as follows.

In Table 2, the mean scores of the 40 items are all above 4.50, indicating that the participants had acquired all the items in the questionnaire. In this sense, it can be inferred that the participants' failure in the final experiment is the results of attrition, but not imperfect learning. According to the std. deviations of the 4 stages, the differences among the mean scores of the four stages are slim, which means the participants involved in the pilot study have a nearly equal mastery on these 40 English interrogations of 4 stages.

In Table 3, the sig. value among stages is listed.

As shown in it, the sig. value is 0.212 ( $p>0.05)$, which indicates that participants involved in the pilot study all mastered these English interrogations of the 4 stages equally.

In the pilot study, the internal consistency reliability of the questionnaire was measured to examine the reliability of the present study statistically.

In Table 4, the Cronbach's alpha coefficients of the items in every stage are shown ranging from 0.70 to 0.81 , which indicates that there is strong consistency of results across items in every stage and the questionnaire is valid to be used in the final survey.

\section{Results and Discussion}

\subsection{Statistical Descriptions of the Results in the Final Survey}

Referring to the criterion mentioned in 3.2, we excluded the data of the participants who graduated in English major or received master program study or, apparently had not taken the test seriously. Among 306 questionnaires, 243 of them are valid. 
Table 1. Original list of the sentences used in the questionnaire.

\begin{tabular}{|c|c|c|}
\hline Stage & Sentences & Correctness \\
\hline \multirow{10}{*}{1} & *What’s your name? (Hatch, 1978) & $\sqrt{ }$ \\
\hline & He goes where to the movie? & $x$ \\
\hline & "He writing on the book? (Ellis, 1999) & $x$ \\
\hline & He is who? & $x$ \\
\hline & "What’s this? (Ellis, 1999) & $\sqrt{ }$ \\
\hline & "What are you doing? (Hatch, 1978) & $\sqrt{ }$ \\
\hline & *Eve is doing what there? (Ravem, 1974) & $\times$ \\
\hline & *How are you? (Hatch, 1978) & $\sqrt{ }$ \\
\hline & You how old age? & $x$ \\
\hline & "What color of your bag? (Hatch, 1978) & $x$ \\
\hline \multirow{10}{*}{2} & "How I can find Rune? (Ravem, 1974) & $x$ \\
\hline & "What you going to build next week? (Ravem, 1974) & $\times$ \\
\hline & What am I do? & $x$ \\
\hline & What does he does? & $x$ \\
\hline & Which way should they choose? & $\sqrt{ }$ \\
\hline & "What “tub” mean? (Ellis, 1999) & $x$ \\
\hline & Do you have a pen? & $\sqrt{ }$ \\
\hline & "How he became a doctor? (Ravem, 1974) & $\times$ \\
\hline & *Are you going to make it with me? (Klima \& Belluge, 1966) & $\sqrt{ }$ \\
\hline & Can you speak Chinese? & $\sqrt{ }$ \\
\hline \multirow{10}{*}{3} & Why can you don't like swimming? & $x$ \\
\hline & Why not find a book to read? & $\sqrt{ }$ \\
\hline & "Did not you say it to dad? (Ravem, 1968) & $\sqrt{ }$ \\
\hline & "Why we can't go to London now? (Ravem, 1974) & $x$ \\
\hline & ${ }^{*}$ Why are you not live in Oslo? (Ravem, 1968) & $\times$ \\
\hline & Does he not wear the glass? & $x$ \\
\hline & Did you not see that in my book? & $\times$ \\
\hline & "Is he not black hair? (Hatch, 1978) & $x$ \\
\hline & Why don't you put it on the desk? & $\sqrt{ }$ \\
\hline & "Why I mustn't sit on the floor? (Ravem, 1974) & $x$ \\
\hline \multirow{10}{*}{4} & Can you tell me where do you live? & $\times$ \\
\hline & Can you tell me which one do you like best? & $x$ \\
\hline & "What makes you happy? (Klima \& Belluge, 1966) & $\sqrt{ }$ \\
\hline & Can you tell me how many students are there in our class? & $\times$ \\
\hline & ${ }^{*}$ Can you guess whom did he play with? (Hakuta, 1974) & $\times$ \\
\hline & Does he know which class are you in? & $\times$ \\
\hline & "Who took them all down? (Hakuta, 1974) & $\sqrt{ }$ \\
\hline & Where do you know the teacher was? & $\sqrt{ }$ \\
\hline & "What did you think how they would study English? (Hakuta, 1974) & $\times$ \\
\hline & Do you know which city does he like best? & $\times$ \\
\hline
\end{tabular}

Note: "V": Grammatically correct " $\times$ ": Grammatically incorrect. 
Table 2. Descriptive statistics of the 4 stages in the pilot study.

\begin{tabular}{ccccc}
\hline Stage & $\mathrm{N}$ & Mean & Std. Deviation & Std. Error \\
\hline 1 & 10 & 4.84 & 0.12 & 0.04 \\
2 & 10 & 4.77 & 0.06 & 0.02 \\
3 & 10 & 4.76 & 0.09 & 0.02 \\
4 & 10 & 4.75 & 0.11 & 0.03 \\
Total & 40 & 4.78 & 0.10 & 0.02 \\
\hline
\end{tabular}

Table 3. Analysis of variance of the 4 stages in the pilot study.

\begin{tabular}{cccccc}
\hline & Sum of Squares & df & Mean Square & F & Sig. \\
\hline Among Stages & 0.04 & 3 & 0.02 & 1.58 & 0.212 \\
Within Stages & 0.34 & 36 & 0.01 & & \\
Total & 0.38 & 39 & & \\
\hline
\end{tabular}

Table 4. Reliability statistics of items in 4 stages.

\begin{tabular}{cccc}
\hline Stage & Cronbach's Alpha & Cronbach's Alpha Based on Standardized Items & N of Items \\
\hline 1 & 0.81 & 0.81 & 10 \\
2 & 0.74 & 0.72 & 10 \\
3 & 0.78 & 0.76 & 10 \\
4 & 0.70 & 0.71 & 10 \\
\hline
\end{tabular}

Since a five-scale Likert system was adopted in the grammaticality judgment task, numerical scores were assigned to each item when the task was processed. When an item was grammatically correct, "Definitely correct" scored 5, "Fairly correct" scored 4, "Not sure” scored 3, "Fairly incorrect” scored 2 and "Definitely incorrect" scored 1, and vice versa. Based on the concept that the items with the lowest accuracy rate were considered to be subject to attrition firstly. The accuracy order drawn was reverse to attrition order on the grounds that the more an item was judged accurately, the later it was attrited.

The 243 participants' performance on every item in each stage is obtained. In regard to mean scores, the highest one is 4.99 while the lowest one is 1.83 . The standard deviations of the 40 items also range from 0.09 to 1.71. Plus, it is observed that the mean scores in the four stages declined gradually. The ten items in the first stage are retained best and those in the fourth stage are retained worst.

In Figure 1, we compare the mean scores of two groups yielded respectively from the pilot study and the survey. The 40 items in the figure correspond to the numbers of sentences in the appendix, with item 1 to item 10 representing the first acquisition stage, item 11 to item 20 representing the second one, item 21 to item 30 representing the third one and item 31 to item 40 representing the fourth one. It is found that on the whole the mean scores are high and the variation of the mean scores is quite steady in pilot study, while the mean scores are lower and the mean scores fluctuates to a great extent in the final survey, which may lead to a conclusion that the interrogative structures in the questionnaire had been somehow attrited when the final survey was undertaken and the attrition degree on the items differed considerably.

The statistical data in Table 5 show a significant difference $(p=0.000<0.05)$ among the mean scores of four stages, which manifests that the differences among stages are due to the unbalanced retention of the interrogation items, but not caused by any error or by chance. To be further, when the survey happened, the participants involved in the survey no longer had the same mastery of the interrogation items. The participants' English interrogative structures were attrited to some extent after at least two years' disuse.

With Post Hoc Tests of one-way ANOVA, the mean scores of four stages are compared in Table 6. It is 


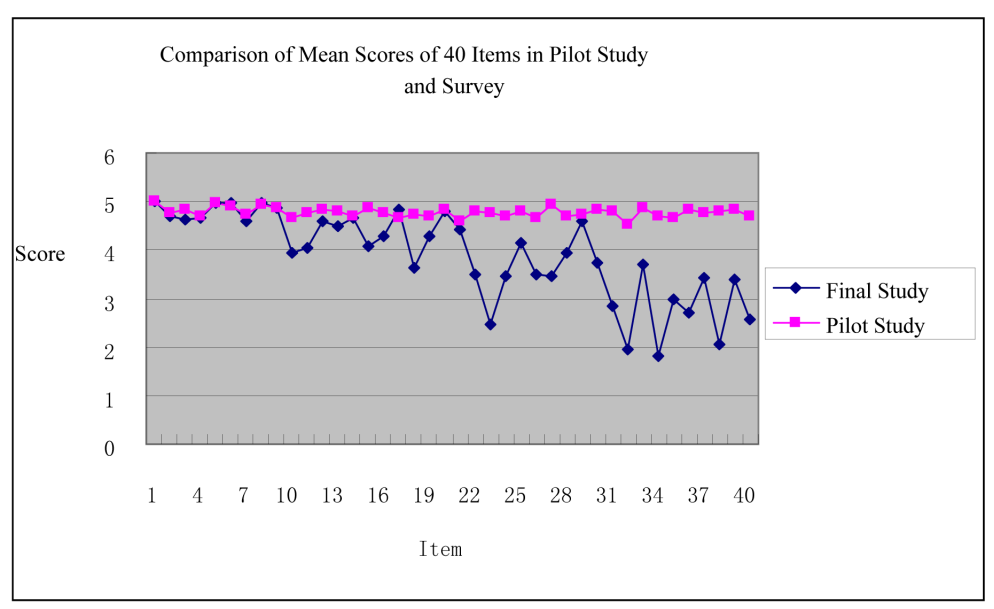

Figure 1. Comparison of mean scores of 40 items in pilot study and survey.

Table 5. Analysis of variance for 4 stages in the survey.

\begin{tabular}{ccccc}
\hline & Sum of Squares & df & Mean Square & Sig. \\
Between Stages & 22.79 & 3 & 7.60 & 29.24 \\
Within Groups & 9.35 & 36 & 0.26 \\
Total & 32.14 & 39 & & 0.000 \\
\hline
\end{tabular}

Table 6. Multiple comparisons between stages in the survey.

\begin{tabular}{cccc}
\hline Between Stages & Mean Difference & Std. Error & Sig. \\
\hline Stage 1 - Stage 2 & 0.36 & 0.23 & 0.123 \\
Stage 1 - Stage 3 & 1.01 & 0.23 & 0.000 \\
Stage 1 - Stage 4 & 1.99 & 0.23 & 0.000 \\
Stage 2 - Stage 3 & 0.65 & 0.23 & 0.007 \\
Stage 2 - Stage 4 & 1.63 & 0.23 & 0.000 \\
Stage 3 - Stage 4 & 0.98 & 0.23 & 0.000 \\
\hline
\end{tabular}

observed that the difference between stage 1 and stage 2 is not significant in a statistical sense $(p=0.123>0.05)$, while the differences between stage 2 and stage 3 , as well as between stage 3 and stage 4 are all at significant level $(p($ Stage $2-3)=0.007<0.05$; $p($ Stage $3-4)=0.000<0.05)$. It can be concluded that when the final survey was conducted, participants had a nearly equal mastery of the items in stage 1 and stage 2 , while their mastery of the items in other three stages differed greatly.

\subsection{The Attrition Sequence of English Interrogations Yielded by the Study}

The statistical data in 4.1 lead to the accuracy order of items in the 4 stages, that is, Stage $1 \approx />$ Stage $2>$ Stage $3>$ Stage 4, which indicates that items in stage 1 score most and then those in stage 2 , stage 3 and stage 4 . Based on the concept that the items with the lowest accuracy rate are considered to be subject to attrition firstly, and on the ground of the accuracy order of the items in the 4 stages, the attrition sequence of English interrogations in Chinese Context can be simply generalized as follows:

Stage $4>$ Stage $3>$ Stage $2 \approx />$ Stage 1 (">” means "prior to be attrited")

This pattern represents that the interrogative structures in stage 4 are most sensitive to attrition, followed by those in stage 3, stage 2 and finally stage 1 . 
Now, it is necessary for us to compare this sequence with the acquisition sequence. As reviewed in 2.1, the acquisition sequence of English interrogations both for L1 and L2 learners has been identified as follows: Stage $1>$ Stage $2>$ Stage $3>$ Stage 4 (">” means "precede to acquire"). Referring to the attrition sequence above, the attrition sequence of English interrogations roughly reflects the inversed pattern of acquisition sequence in Chinese context, which approximately echoes with the assumption of the Regression Hypothesis.

However, there is no significant difference detected between the mean scores of stage 1 and stage 2 as indicated in Table 5 ( $p=0.123>0.05$ ), which may be caused by the following two reasons.

First, items in stage 1 and stage 2 fall into the same category, i.e. simple and basic positive interrogations. It is natural for the participants to perform nearly equally well on the items in the first two stages.

Second, some items in stage 1 and stage 2, such as “*Eve is doing what there?”, "He is who?" “*He writing on the book?" "*How I can find Rune?” “*How he became a doctor?” "*What "tub' mean?” and "*What you going to build next week?”, are also acceptable to a certain degree in colloquial speech, which may interfere with the participants' performance in the task and accordingly impact the attrition sequence, although we stress to the participants clearly that they should judge the sentences by the criterion of 'written grammatical normal'in the instruction of the questionnaire.

When it comes to this observed sequence, five explanations may be employed to account for it.

First, the acquisition sequence of English interrogations both for L1 and L2 learners has been identified as follows: Stage $1>$ Stage $2>$ Stage $3>$ Stage 4 (">> means "precede to acquire"). Compared with the attrition sequence obtained from the present study (Stage $4>$ Stage $3>$ Stage $2 \approx />$ Stage 1 ), we may find that the order in which attrition occurs is roughly opposite to the order in which language is acquired, which is in line with Jakobson's Regression Hypothesis. In reference to the hypothesis, there exist two versions. One states that the order in which attrition occurs is opposite to the order in which language is acquired, which can just be exemplified by the finding of this study. The other version of Regression Hypothesis claims that what has been learned best, i.e. most often used or reinforced, will be most resistant to loss (Yoshitomi, 1999). As shown in the pilot study, the mean score of items in stage 1 is highest and that in stage 4 is the lowest. Thus, items in stage 1 , which have been learned best, prove to be most resistant to attrition, and vice versa in stage 4 .

As a most prevalent theory of describing the nature of the attrition process, Regression Hypothesis is testified by many researchers in different language contexts. de Bot and Weltens (1991) confirm that language components may be lost in the reverse order in which they are acquired, i.e. the attrition sequence is "a recapitulation in reverse of the acquisition sequence” (Hansen, 1980: p. 169). With respect to syntax, such as interrogative structures, first-learned, basic syntactic patterns are retained longest, which has also verified by the findings of the present study.

The precedent studies have found evidence for this hypothesis in English and some Indo-European language contexts. However, it is not applicable to all linguistic structures or language contexts, and its predictive power to these cases is still in need of verification. Meanwhile, the hypothesis is vulnerable to variables. Hansen (1999) summarizes the variables prone to affect mechanism of the Regression Hypothesis including frequency, features of the attriting language, dominant language, linguistic markedness, language universals and the sequence of acquisition as well.

Second, based on Chomsky's universal grammar, Ross puts forward a model named Centralness-Peripheral system (as shown in Figure 2) (Hatch, 1976). According to this model, "centralness" refers to the category of basic and simple sentences, which is the "core” of a language. "Peripheral" refers to the group of embedded and compound sentences derived from basic and simple ones. The system is illuminated with the following seven hypotheses:

Hypothesis 1: There are central parts and peripheral parts in a language.

Hypothesis 2: In the first language acquisition, children will learn the central parts first.

Hypothesis 3: In the second language acquisition, learners will learn the central parts first.

Hypothesis 4: The peripheral parts will be first lost in an aphasia patient.

Hypothesis 5: The peripheral parts will be first attrited in first and second language attrition.

Hypothesis 6: The central parts will be retained well in Pidgin and Creole.

Hypothesis 7: The variations in central parts are much less than those happened in peripheral parts.

When it comes to the present study, the interrogative items involved in the questionnaire fall into two main structure categories. Some of them belong to basic and simple sentences such as the items in stage 1, stage 2 and stage 3 while the others fall into embedded-sentence category such as the items in stage 4 . On the ground of the 


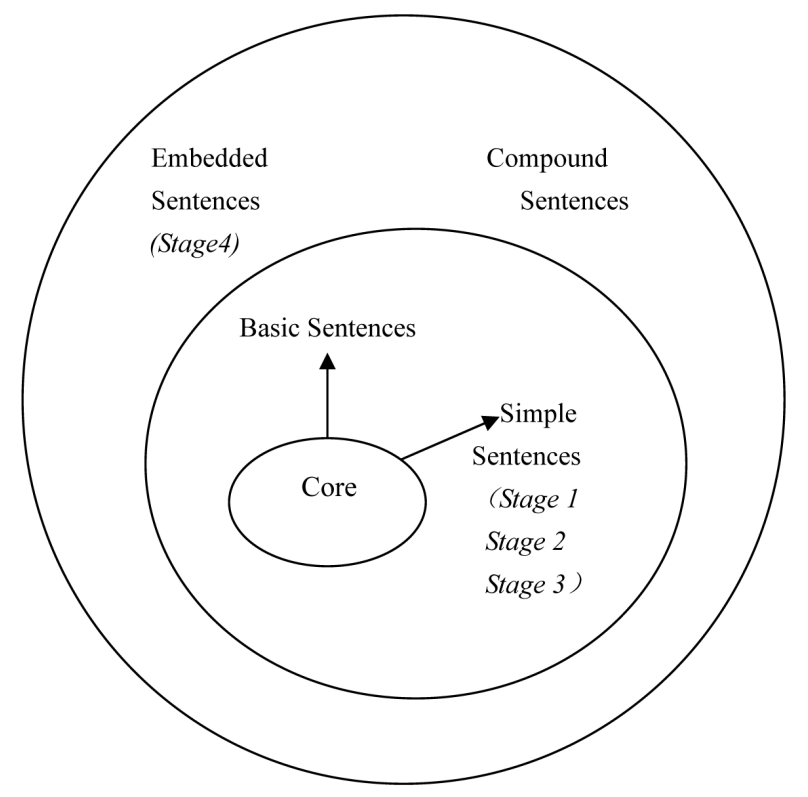

Figure 2. Ross’s centralness-peripheral system.

fifth hypothesis of Centralness-Peripheral system, the peripheral parts will be first attrited in both first and second language attrition. The attrition sequence obtained from the present study indicated that items in stage 4 were attrited first and most (Stage $4>$ Stage $3>$ Stage $2 \approx>>$ Stage 1 ), which was consistent with the hypotheses of Ross's Centralness-Peripheral system. Furthermore, hypothesis 7 claims that the variations in central parts are much less than those happened in peripheral parts, which can account for why the interrogative structures in stage 1,2 and 3 can retain longer than those in stage 4.

Third, Interference Theory may play its role in influencing the attrition process of English interrogations (see the section on interference in Ecke, 2004). In the light of this theory, information which is acquired in the past can interfere with the learning and recall of more recent or novel information. Simply put, this theory suggests that people forget a particular thing " $\mathrm{A}$ " because there is a memory of "B" which interferes with the recall of "A" (Weltens, 1989). In regard to the findings of this study, this theory functions to a great extent. When a learner masters the interrogation items in stage 2 and stage 3, he may over generalize that interrogations are formed with a subject-verb inversion. Thus, when he constructs embedded interrogative sentences, he naturally inverts the subject and the verb of the embedded clauses and generates such ungrammatical sentences as "* Can you tell me who are you?" Simply speaking, the rule of generating a simple (or basic) interrogative sentence in his mind interferes with his acquisition (as well as attrition) of embedded interrogative sentences. Furthermore, in the light of the mean scores of 4 stages in the final survey, items in stage 1 and stage 2 were retained quite well with mean scores being 4.73 and 4.37 respectively, which meant that participants retained well the rules of generating interrogation items in stage 1 and stage 2. However, it is just the rules that interfere with the retention and retrieval of rules of generating embedded interrogations. From the final survey, the mean score of items in stage 4 is 2.75 , indicating that the attrition in stage 4 is partly due to the interference of the rules of forming interrogation items in stage 1 and stage 2 .

Fourth, in the circle of second language acquisition, learner's L1 is an important determinant factor affecting his acquisition and attrition of a L2 - and language acquisition is actually regarded to be the process of language transfer. In this sense, the transfer of patterns from the native language is undoubtedly one of the major sources of errors in learner language. In terms of the collected questionnaires and findings of the present study, some interrogative items were wrongly judged. And, most of these wrongly-judged items fell into the products of transfer such as "He is who?" It is a typical transfer of Chinese syntactic order since we say "Ta shi shui?" (Who is he?) in Chinese. It is the same with such sentences as "“* He writing on the book?" "“* Why we can't go to London now?" “* Eve is doing what there?" as well as "You how old age?"

Fifth, there are other causes responsible for participants' errors too, one of which is overgeneralization of target-language rules. According to the questionnaire, the interrogations in stage 1 and stage 2 were retained best, 
which means the participants remember clearly an interrogation is formed with subject and verb inverted. Based on the belief, it is natural for them to judge such embedded sentences as "Can you tell me which class are you in?" correct. It is the overgeneralization of the rules of forming simple and basic interrogations. In this sense, a conclusion can be reached that transfer and overgeneralization are important factors affecting language attrition.

\section{Conclusion and Limitations}

Based on the observed data in the pilot study and the survey, this research explores the Chinese EFL learners' attrition sequence of English interrogative structures. The following major findings are accordingly obtained.

The EFL learners' attrition sequence of English interrogations is identified. It is detected that the attrition sequence roughly reflects the inversed pattern of acquisition sequence of English interrogations in Chinese context, which echoes with Jakobson's Regression Hypothesis. That is, language components might be lost in the reverse order in which they were acquired. Accordingly, learners are expected to timely and regularly review their acquired language knowledge prone to attrition, which will enhance the likelihood of language skills maintenance. In addition, it is hoped that understanding some of the dynamic processes of language retention and attrition will increase teachers' and learners' awareness and ability to make their own personal observations and to help keep EFL learners' language abilities.

Methodologically speaking, there are still limitations impeding the study to get a better result and thus several suggestions are proposed for further investigation.

Attrition, by its nature, is rather difficult to be investigated empirically. Hence, a longitudinal paradigm is preferable in language attrition research, where the learner's dynamic process of acquisition and attrition can be traced. Such studies are usually only possible as single or multiple case studies (see Ecke \& Hall, 2013; Opitz, 2013 for recent examples). However, it is impossible for us to conduct such a longitudinal study with hundreds of participants which will last several years. The present study, therefore, resorted to a cross-sectional paradigm with a pilot study involved, where participants PLPAs were roughly presupposed by means of consulting those of the equivalent participants in the pilot study. However, to which extent can the PLPAs of the equivalent participants presuppose those of participants? It is a problem under disputations. Thus a longitudinal method should be adopted as a best way to examine the learner's attrition in future studies.

\section{Acknowledgements}

Special thanks will be given to Professor Ni Chuan-bin, Professor Ma Guang-hui and Professor Cai Han-song, whose illuminating instructions, invaluable suggestion and rigorous scholarship have been with me all the way during the research. Thanks for the financial support of the Program for the Philosophy and Social Sciences Research of Higher Learning Institutions of Jiangsu Province (Number: 2014SJD127).

\section{References}

Adams, M. (1978). Methodology for Examining Second Language Acquisition. In E. Hatch (Ed.), Second Language Acquisition: A Book of Readings (pp. 277-296). Rowley, MA: Newbury House.

Cazden, C. (1975). Second Language Acquisition Sequence in Children, Adolescents and Adults. Final Report in US Department of Health, Education and Welfare, New York, June.

de Bot, K., \& Weltens, B. (1991). Recapitulation, Regression, and Language Loss. In H. W. Seliger, \& R. M. Vago (Eds.), First Language Attrition (pp. 31-51). Cambridge: Cambridge University Press. http://dx.doi.org/10.1017/CBO9780511620720.003

Ecke, P. (2004). Language Attrition and Theories of Forgetting: A Cross-Disciplinary Review. International Journal of Bilingualism, 8, 321-354. http://dx.doi.org/10.1177/13670069040080030901

Ecke, P., \& Hall, C. J. (2013). Tracking Tip-of-the-Tongue States in a Multilingual Speaker: Evidence of Attrition or Instability in Lexical Systems? International Journal of Bilingualism, 17, 734-751. http://dx.doi.org/10.1177/1367006912454623

Ellis, R. (1994). The Study of Second Language Acquisition. Oxford: Oxford University Press.

Ellis, R. (1999). Understanding Second Language Acquisition. Shanghai: Shanghai Foreign Language Education Press.

Hakuta, K. (1974). Prefabricated Patterns and the Emergence of Structure in Second Language Acquisition. Language Learning, 24, 287-297. http://dx.doi.org/10.1111/j.1467-1770.1974.tb00509.x 
Hansen, L. (1980). Learning and Forgetting a Second Language: The Acquisition, Loss and Reacquisition of Hindu-Urdu Negative Structures by English-Speaking Children. Ph.D. Dissertation, Berkeley, CA: University of California.

Hansen, L. (Ed.) (1999). Second Language Attrition in Japanese Contexts. Oxford: Oxford University Press.

Hatch, E., \& Wagner-Gough, J. (1976). Explaining Sequence and Variation in Second Language Acquisition. Language Learning, 4, 39-47.

Hatch, E. (Ed.) (1978). Second Language Acquisition: A Book of Readings. Rowley, MA: Newbury House.

Hayashi, B. (1999). Testing the Regression Hypothesis: The Remains of the Japanese Negation System in Micronesia. In L. Hansen (Ed.), Second Language Attrition: Evidence from Japanese Contexts (pp. 154-168). Oxford: Oxford University Press.

Hedgcock, J. (1991). Foreign Language Retention and Attrition: A Study of Regression Models. Foreign Language Annals, 24, 43-55. http://dx.doi.org/10.1111/j.1944-9720.1991.tb00440.x

Jakobson, R. (1941). Child Language, Aphasia, and Phonological Universals. The Hague: Mouton Publishers.

Jimenez, A. F. J. (2003). Linguistic and Psychological Dimensions of Second Language Attrition during and after a Study Abroad Experience. Ph.D. Dissertation, Pennsylvania: The Pennsylvania State University.

Klima, E. S., \& Bellugi, U. (1966). Syntactic Regulation in the Speech of Children. In J. Lyons, \& R. J. Wales (Eds.), Psycholinguistic Papers (pp. 183-203). Edinburgh: Edinburgh University Press.

Li, S. Y. (2008). An Empirical Study on the Attrition Sequence of English Negation in Chinese Context. Master Dissertation, Nanjing: Nanjing Normal University.

Ni, C. B., \& Yan, J. R. (2006). Analysis of the Factors Affecting Foreign/Second Language Attrition. Foreign Language Teaching and Research, 1, 50-56.

Olshtain, E. (1989). Is Second Language Attrition the Reversal of Second Language Acquisition? SSLA, 11, 151-165.

Opitz, C. (2013). A Dynamic Perspective on Late Bilinguals’ Linguistic Development in an L2 Environment. International Journal of Bilingualism, 17, 701-715. http://dx.doi.org/10.1177/1367006912454621

Paradis, M. (1993). Linguistic, Psycholinguistic, and Neurolinguistic Aspects of Interference in Bilingual Speakers: The Activation Threshold Hypothesis. International Journal of Psycholinguistics, 9, 133-145.

Pauwels, A. F. (1986). Diglossia, Immigrant Dialects and Language Maintenance in Australia: The Case of Limburgs and Swabian. Journal of Multilingual and Multicultural Development, 7, 13-30. http://dx.doi.org/10.1080/01434632.1986.9994227

Ravem, R. (1968). Language Acquisition in a Second Language Environment. International Review of Applied Linguistics in Language Teaching, 6, 175-185. http://dx.doi.org/10.1515/iral.1968.6.1-4.175

Ravem, R. (1974). The Development of Wh-Questions in First and Second Language Learners. In J. C. Richard (Ed.), Error Analysis: Perspectives on Second Language Acquisition (pp. 115-126). London: Longman.

Schmidt, A. (1985). Young People’s Dyirbal: An Example of Language Death from Australia. Cambridge: CUP.

Vechter, A., Lapkin, A., \& Argue, V. (1990). Second Language Retention: A Summary of the Issues. The Canadian Modern Language Review, 46, 189-203.

Weltens, B. (1989). The Attrition of French as a Foreign Language. Dordrecht: Foris Publications. http://dx.doi.org/10.1515/9783111395937

Yoshitomi, A. (1999). On the Loss of English as a Second Language by Japanese Returnee Children. In L. Hansen (Ed.), Second Language Attrition: Evidence from Japanese Contexts (pp. 21-58). Oxford: Oxford University Press. 
Appendix

\begin{tabular}{|c|c|c|c|c|c|c|}
\hline & \multirow{2}{*}{ Sentences } & A & B & $\mathrm{C}$ & $\mathrm{D}$ & $\mathrm{E}$ \\
\hline & & Definitely correct & Fairly correct & Not sure & Fairly incorrect & Definitely incorrect \\
\hline 1 & What's your name? & & & & & \\
\hline 2 & Can you tell me where do you live? & & & & & \\
\hline 3 & How I can find Rune? & & & & & \\
\hline 4 & Why can you don't like swimming? & & & & & \\
\hline 5 & He goes where to the movie? & & & & & \\
\hline 6 & Why not find a book to read? & & & & & \\
\hline 7 & He writing on the book? & & & & & \\
\hline 8 & What you going to build next week? & & & & & \\
\hline 9 & He is who? & & & & & \\
\hline 10 & Did not you say it to dad? & & & & & \\
\hline 11 & Can you tell me which one do you like best? & & & & & \\
\hline 12 & What makes you happy? & & & & & \\
\hline 13 & Why we can't go to London now? & & & & & \\
\hline 14 & What am I do? & & & & & \\
\hline 15 & $\begin{array}{c}\text { Can you tell me how many students are there in } \\
\text { our class? }\end{array}$ & & & & & \\
\hline 16 & What does he does? & & & & & \\
\hline 17 & Why are you not live in Oslo? & & & & & \\
\hline 18 & What's this? & & & & & \\
\hline 19 & Can you guess whom did he play with? & & & & & \\
\hline 20 & Does he not wear the glass? & & & & & \\
\hline 21 & Which way should they choose? & & & & & \\
\hline 22 & What are you doing? & & & & & \\
\hline 23 & Does he know which class are you in? & & & & & \\
\hline 24 & Did you not see that in my book? & & & & & \\
\hline 25 & Who took them all down? & & & & & \\
\hline 26 & Eve is doing what there? & & & & & \\
\hline 27 & What "tub" mean? & & & & & \\
\hline 28 & How are you? & & & & & \\
\hline 29 & Do you have a pen? & & & & & \\
\hline 30 & Is he not black hair? & & & & & \\
\hline 31 & How he became a doctor? & & & & & \\
\hline 32 & Where do you know the teacher was? & & & & & \\
\hline 33 & You how old age? & & & & & \\
\hline 34 & Why don't you put it on the desk? & & & & & \\
\hline 35 & Are you going to make it with me? & & & & & \\
\hline 36 & $\begin{array}{l}\text { What did you think how they would study } \\
\text { English? }\end{array}$ & & & & & \\
\hline 37 & What color of your bag? & & & & & \\
\hline 38 & Why I mustn't sit on the floor? & & & & & \\
\hline 39 & Do you know which city does he like best? & & & & & \\
\hline 40 & Can you speak Chinese? & & & & & \\
\hline
\end{tabular}


Scientific Research Publishing (SCIRP) is one of the largest Open Access journal publishers. It is currently publishing more than 200 open access, online, peer-reviewed journals covering a wide range of academic disciplines. SCIRP serves the worldwide academic communities and contributes to the progress and application of science with its publication.

Other selected journals from SCIRP are listed as below. Submit your manuscript to us via either submit@scirp.org or Online Submission Portal.
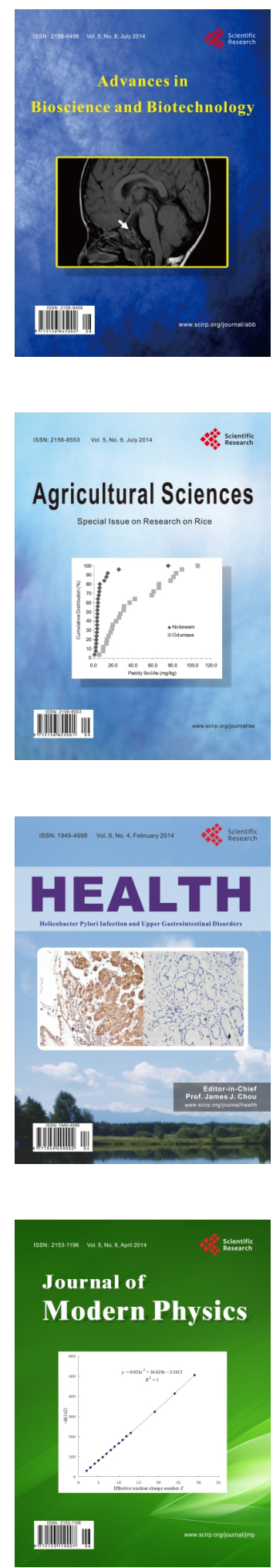
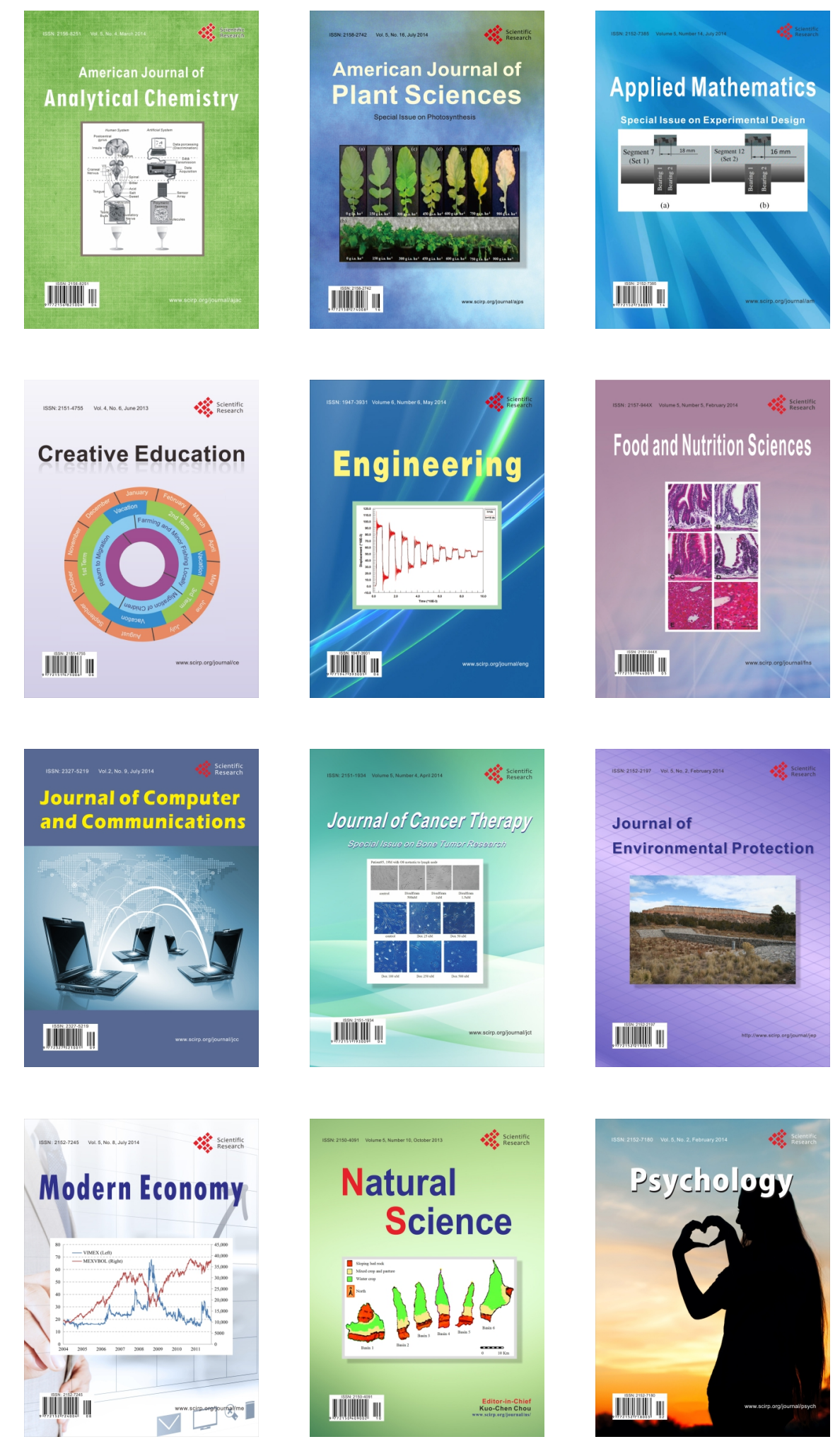